\title{
Avaliação do grau de conhecimento sobre cuidados paliativos e dor dos estudantes de medicina em uma faculdade particular de São Luís/MA
}

\author{
Evaluation of the knowledge degree on palliative care and pain of students of medicine in \\ a particular college of São Luís/MA
}

\author{
Clarisse Sereno Loiola Braide ${ }^{\text {, }}$ Plinio da Cunha Leal ${ }^{2}$, Mércia Helena Salgado Leite de Souza ${ }^{1}$
}

\begin{abstract}
Resumo: Observa-se atualmente um cenário onde há um progressivo envelhecimento populacional, associado a um predomínio de doenças crônico-degenerativas de evolução lenta. Dentro deste contexto, os Cuidados Paliativos se inserem como uma medida extremamente necessária, de promover qualidade de vida, prevenir e aliviar o sofrimento de indivíduos e de seus familiares. Com base nesta problemática, surge o interesse em avaliar a partir de um questionário, como os estudantes que irão se formar em medicina se sentem a respeito do conhecimento e tratamento da dor, e como se comunicam com seus pacientes. Registros da literatura apontam que o médico tem sua formação acadêmica toda voltada para o diagnóstico e tratamento de doenças, assim, quando defronte de um paciente necessitado de Cuidados Paliativos, o foco deixa de ser a doença e passa a ser a pessoa doente. De forma a garantir não só alívio de sintomas desconfortáveis, mas também a dignidade de vida até o fim. Trata-se de um estudo longitudinal, prospectivo, de caráter quantitativo, realizado na Universidade Ceuma, em São Luís- MA, com estudantes de medicina do primeiro ao décimo segundo período, aprovado pelo Comitê de Ética e registrado sob o número de parecer 2.101.716. Foram avaliados 232 acadêmicos a partir de um questionário com perguntas fechadas, analisadas de acordo com os seguintes aspectos: formação técnica, percepção dos conhecimentos fisiopatológicos, semiologia e terapêutica associadas a dor e cuidados paliativos. A idade dos participantes variou entre 17 e 32 anos com prevalência de $52,6 \%$ com a faixa etária de $21|---| 24$ anos, e quanto ao gênero, a ocorrência de $69,0 \%$ do sexo feminino. A maioria dos alunos não conhece a definição de Cuidados Paliativos da Organização Mundial de Saúde (61\%), e não se sente à vontade para comunicar más notícias aos pacientes e familiares. Assim, acredita-se que a criação de uma disciplina específica para Cuidados Paliativos, poderia sanar as deficiências educacionais aqui levantadas nos graduandos e eventuais egressos.
\end{abstract}

Palavras-Chave: Cuidados Paliativos. Dor. Educação Médica.

\begin{abstract}
There is currently a scenario where there's a progressive population ageing, associated to a predominance of chronic degenerative diseases of slow evolution. Within this context, the palliative care is included as a measure extremely necessary, promote quality of life, prevent and relieve the suffering of individuals and their families. Based on this, the interest in assessing from a questionnaire, as students who will graduate in medicine feel about the knowledge and treatment of pain, and how to communicate with their patients. Records from the literature indicate that the doctor has your all's education focused on the diagnosis and treatment of diseases, so, when in front of a patient in need of palliative care, the focus is no longer the disease and becomes the person sick. In order to ensure not only relief from uncomfortable symptoms, but also the dignity of life until the end. It is a longitudinal study, quantitative and prospective. This study was developed at Ceuma University, in São Luís-MA, with medical students of first to the twelfth period, approved by the Ethics Committee registered under the number of opinions 2.101.716. We evaluated 232 students from a questionnaire with closed questions, analyzed according to the following aspects: technical training, perception of pathophysiological knowledge, semiology and therapeutics associated with pain and palliative care. The age of participants ranged between 17 and 32 years, with a prevalence of $52.6 \%$ in the age group of $21-24$ years old, and $69.0 \%$ of the female gender. Most students do not know the definition of Palliative Care of the World Health Organization (61\%), and don't feel comfortable communicating bad news to patients and family members. Thus, it is believed that the creation of a specific discipline for Palliative Care, could remedy the educational deficiencies raised here among graduates and eventual graduates.
\end{abstract}

Keywords: Palliative care. Pain. Medical Education.

\footnotetext{
${ }^{1}$ Universidade Ceuma, São Luís, MA, Brasil.

2 Universidade Federal do Maranhão, São Luís, MA, Brasil.

* Autor correspondente - Rua Josué Montello n¹, Renascença II - São Luís-MA. CEP 65.075-120.

Telefone: +55 (98) 98868-5248. E-mail: mercia_hsls@hotmail.com
} 


\section{Introdução}

Os Cuidados Paliativos são definidos pela Organização Mundial de Saúde (OMS) como: "O cuidado ativo e total nas doenças que não respondem ao tratamento curativo. O controle da dor, de outros sintomas e os problemas psicológicos, social e espiritual são os mais importantes. A sua meta é melhorar a qualidade de vida para os pacientes e seus familiares. Muitos aspectos dos Cuidados Paliativos são aplicáveis mais cedo, no curso da doença, em conjunto com o tratamento oncológico"1. O acompanhamento é multiprofissional, conta com a participação de: anestesiologistas, clínicos, cirurgiões, psiquiatras, fisioterapeutas, enfermeiros, assistentes sociais e psicólogos, e muitas vezes, um apoio religioso.

No Brasil, os Cuidados Paliativos iniciaram-se em 1990 no Instituto Nacional do Câncer (INCA) no Rio de Janeiro². Atualmente, existem serviços especializados nos estados do Brasil, e três instituições estão envolvidas na divulgação dos Cuidados Paliativos: a Sociedade Brasileira de Anestesiologia (SBA), a Sociedade Brasileira para 0 Estudo da Dor (SBED) e a Academia Nacional de Cuidados Paliativos.

Os pacientes com câncer em fase avançada enfrentam simultaneamente vários problemas. $\mathrm{O}$ conceito denominado dor total abrange vários componentes: a luta contra a doença e seus respectivos tratamentos, os problemas emocionais (raiva, depressão, desesperança, desespero, culpa, proximidade da morte) e a mudança dos planos de sua vida, pois deixam de lado os de longo prazo, fixando-se em metas de curto prazo. A OMS declarou que a dor associada ao câncer é uma emergência médica mundial. A dor é de grande intensidade nos pacientes oncológicos, em casos avançados ocorrem em 50\% a $75 \%$. Alguns pacientes apresentam mais de um tipo de dor. Quanto ao tratamento foi estabelecido no Primeiro Consenso Nacional de Dor Oncológica que os analgésicos opioides deveriam ser a base do tratamento da dor oncológica. É imprescindível para o controle da dor o conhecimento e a utilização da escada analgésica e dos medicamentos específicos, por via oral, em $85 \%$ a $95 \%$ dos pacientes.

A Organização Mundial de Saúde (OMS) definiu em 1990 e revisou em 2002 o conceito de cuidados paliativos, como cuidados ativos e totais ao paciente cuja doença não responde mais ao tratamento curativo. Trata-se de uma abordagem de cuidado diferenciada que visa melhorar a qualidade de vida do paciente e seus familiares, por meio da adequada avaliação e tratamento para alívio da dor e sintomas, além de proporcionar suporte psicossocial e espiritual ${ }^{3}$.

Esta modalidade, tornou-se um modelo de assistência, ensino e pesquisa no cuidado aos pacientes e suas famílias, e tem como alvos pacientes diagnosticados como "fora de possibilidades de cura" 4 . Logo se entende que todo paciente com prognóstico desfavorável de uma doença crônico degenerativa, sem resposta terapêutica curativa, deve ter acesso aos cuidados paliativos.

Os cuidados podem ser prestados em ambientes de internação hospitalar, ambulatorial e domiciliar. A prática adequada dos Cuidados Paliativos preconiza atenção individualizada ao doente e à sua família, busca da excelência no controle de todos os sintomas e prevenção do sofrimento, possibilitando simultaneamente sua maior autonomia e independência ${ }^{5}$. Deve ser adaptada a cada país ou região de acordo com aspectos relevantes como: disponibilidade de recursos materiais $\mathrm{e}$ humanos, tipo de planejamento em saúde existente, aspectos culturais e sociais da população atendida 4 .

O Cuidado Paliativo não se baseia em protocolos, mas em princípios. Não 
se fala mais em terminalidade, mas em doença que ameaça a vida, indica-se o cuidado desde o diagnóstico, expandindo o campo de atuação do médico ${ }^{6}$.

Juntamente com o conceito, a OMS reafirmou em 2002 os princípios que regem a atuação da equipe multiprofissional de Cuidados Paliativos. Essa equipe é formada por profissionais devidamente habilitados e comprometidos com a causa "alívio do sofrimento", adequadamente treinados e experientes no controle de sintomas de natureza não apenas biológica ${ }^{7}$, pessoas que possuem controle dos seus limites de competência dentro de uma equipe, basicamente formada por médicos, enfermeiros, psicólogos, assistentes sociais, fisioterapeutas, terapeutas ocupacionais, nutricionistas, religiosos e voluntários $^{8}$.

\section{Fundamentação Teórica}

O médico tem sua formação acadêmica toda voltada para 0 diagnóstico e tratamento de doenças. Quando defronte de um paciente necessitado de Cuidados Paliativos, onde o foco deixa de ser a doença e passa a ser a pessoa doente nas suas dimensões biológica, psicológica, familiar, social e espiritual, ele obrigatoriamente tem que rever seus conceitos de saber e aprender a trabalhar em equipe ${ }^{9,10}$.

Historicamente, as equipes de saúde se organizam de forma hierarquizada, onde os diferentes profissionais têm seus trabalhos reconhecidos socialmente e, mesmo dentro da própria equipe, de forma diferente. Nesse contexto, o médico é colocado como o detentor do papel predominante, sem que sejam discutidas suas opiniões e condutas ${ }^{11}$. Porém, se ele aceitar passivamente essa situação, todo trabalho necessário para que 0 paciente e sua família tenham seu sofrimento arrefecido, sua dor controlada e uma vida digna até o seu final pode não ter o êxito necessário.

Dentro da sua especificidade, o médico paliativista deve realizar os diagnósticos clínicos. Deve conhecer a doença, sua história natural, os tratamentos já realizados, qual a evolução da doença que seria esperada para aquele paciente especificamente naquele momento. Se necessário for, deve entrar em contato com as outras especialidades médicas, que já trataram ou ainda estejam tratando o paciente, para discutir uma conduta específica. É também do médico a responsabilidade de propor tratamentos, medicamentosos ou não, que sejam compatíveis com o momento de vida do paciente. De forma a garantir não só alívio de sintomas desconfortáveis, mas também a dignidade de vida até o fim. Evitam-se, dessa forma, procedimentos que poderiam aumentar 0 sofrimento do paciente.

Talvez a principal tarefa do médico em uma Equipe de Cuidados Paliativos seja a de coordenar a comunicação entre a equipe, o paciente e sua família. $O$ paciente e a família esperam ouvir do médico sobre o diagnóstico, sobre a proposta terapêutica e sobre o prognóstico da doença. Não devendo o profissional da medicina passar para outros integrantes da equipe a responsabilidade de conversar com 0 paciente e sua família sobre esses aspectos diretamente ligados com a doença.

É ainda muito importante que o médico se comunique de forma eficaz com a equipe sobre esses mesmos aspectos, para que, ao serem questionados pelo paciente e por seus familiares, todos tenham a mesma postura e falem a "mesma língua". Dessa forma, o planejamento terapêutico do paciente será uma construção conjunta de toda a equipe, com participação ativa do paciente e sua família ${ }^{12}$.

Agindo assim, o médico vai funcionar como elemento facilitador para que toda a equipe trabalhe e ajude 0 
paciente a exercer sua autonomia. Com isso, as escolhas e as decisões passam a ser partilhadas entre o paciente, sua família e a Equipe de Cuidados Paliativos. Tornando-se todos corresponsáveis pela produção de saúde e de vida, e cumprindo assim os propósitos de cuidar do paciente de forma integral, individualizada, com foco no seu bem-estar e qualidade de vida, independentemente de quão avançado seja o estado de sua doença.

O novo Código de Ética Médica do $\mathrm{CFM}^{13}$ já incorporou como norma de ontológica (Princípio Fundamental XXII e parágrafo único do artigo 41) a obrigação de todo médico oferecer todos os Cuidados Paliativos aos pacientes portadores de enfermidades terminais, ao mesmo tempo em que veda ao profissional a prática da obstinação terapêutica. Cuidados Paliativos são considerados pelo Conselho Federal de Medicina e Associação Médica Brasileira como área de conhecimento obrigatória em diferentes especialidades médicas e já conta com programas de residência médica em andamento em dois estados brasileiros ${ }^{14-16}$

Evidencia-se a colossal importância do papel do médico, sendo primordial sua presença, principalmente, ao se referir a sua essencial ferramenta de trabalho, o cuidar. As ações do médico compreendem, em sua essência, o cuidado em si, independente do objetivo do tratamento ser preventivo, curativo, de reabilitação ou paliativo ${ }^{17}$. A pesquisa tem como intuito avaliar o grau de conhecimentos dos estudantes de medicina a respeito da dor e dos cuidados paliativos.

\section{Materiais e Métodos}

Trata-se de um estudo longitudinal, prospectivo, de caráter quantitativo, que foi realizado na Universidade Ceuma, unidade Renascença de São Luís - MA. A população de estudo foi os estudantes de medicina do primeiro ao décimo segundo período, no período de setembro de 2017 a dezembro de 2017. Os estudantes foram avaliados a partir de um questionário, com perguntas fechadas. Como critério de exclusão enquadraram-se os estudantes que não aceitaram participar da pesquisa e estudantes fora do período estudado.

Os riscos da pesquisa foram mínimos por se tratar de um estudo quantitativo descritivo. $\mathrm{O}$ possível constrangimento gerado com 0 questionário possibilitava a desistência do voluntário pesquisado a qualquer momento, sem trazer qualquer dano ao mesmo. O questionário permitiu avaliar as dificuldades encontradas dos estudantes de medicina a respeito de cuidados paliativos e no manejo da dor, bem como conhecer seu perfil, a fim orientar a criação de um cenário ímpar de educação e prática médica visando melhora na prática em ambulatórios e hospitais, propiciando uma melhor formação técnica.

O estudo foi aprovado pelo Comitê de Ética em Pesquisa da Universidade Ceuma e registrado sob o número de parecer 2.101.716 e CAAE: 64757916.7.0000.5084.

\section{Resultados}

No total foram avaliados 232 acadêmicos do curso de medicina da Universidade Ceuma, sendo que o estudo mostrou que as idades entre os estudantes variaram entre 17 e 32 e ao dividir as idades por faixa etária, observou uma frequência de 110 (52,6\%) acadêmicos que compunham a faixa etária de 21-24 anos, $48(23,0 \%)$ na faixa etária de 17-20 anos, $27(12,9 \%)$ na faixa etária de 29-32 anos, 24 (11,5\%) na faixa etária de 25-28 anos e 0 com 33 anos ou mais (Figura 1).

No que diz respeito à presença de uma graduação prévia, 55 (23,7\%) responderam afirmativamente e 177 
$(76,3 \%)$ responderam que não apresentavam outra graduação (Figura 2). Dos que responderam positivamente $44(80,0 \%)$ se graduaram anteriormente em curso da área da saúde.

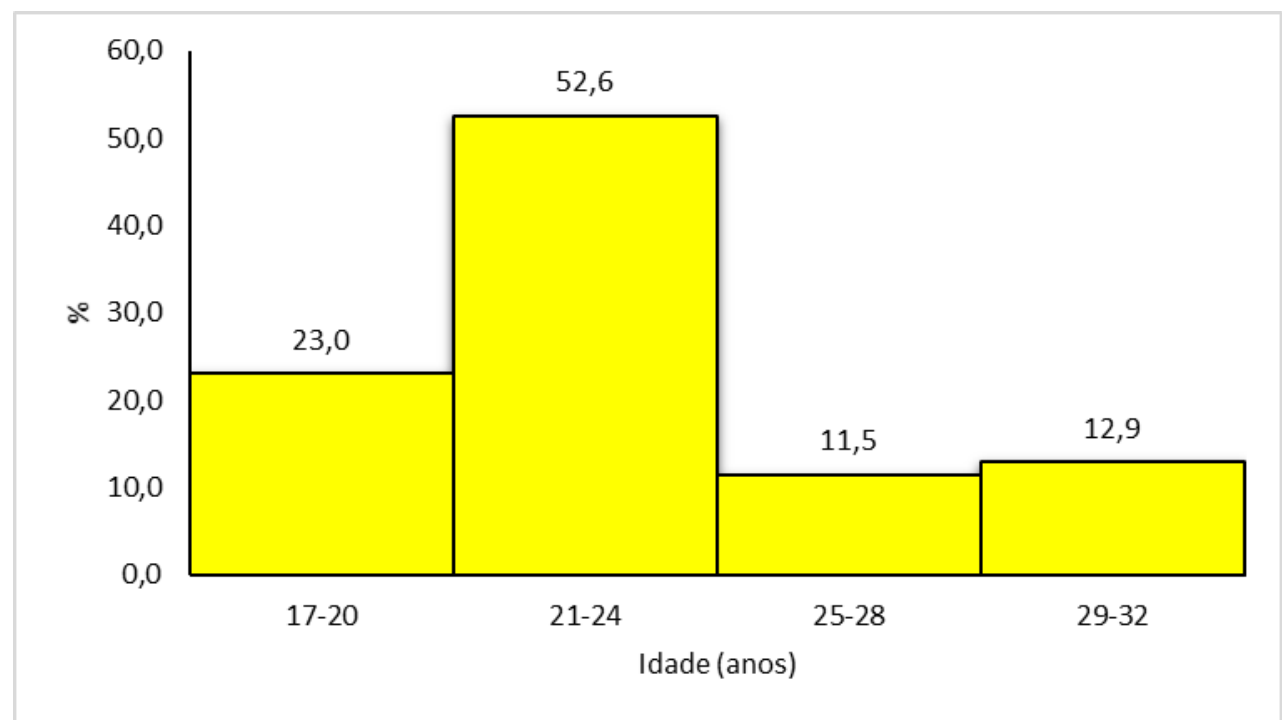

Figura 1. Distribuição das idades dos acadêmicos de medicina da Universidade Ceuma
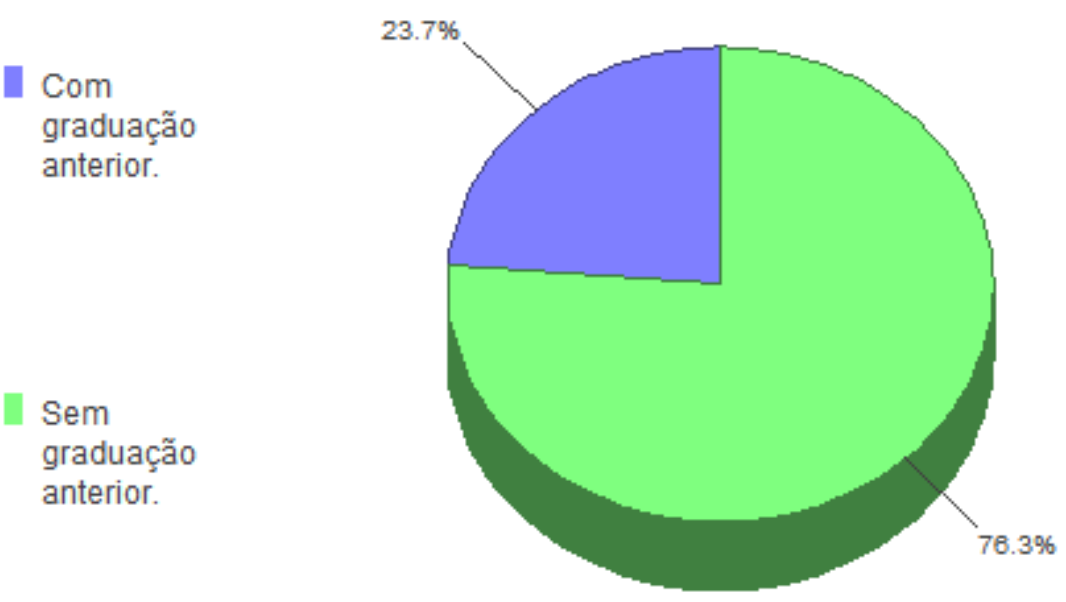

Figura 2. Distribuição quanto a graduação anterior dos acadêmicos de medicina da Universidade Ceuma 
Quanto ao gênero, observou-se a ocorrência de 160 (69,0\%) acadêmicas do sexo feminino e $72(31,0 \%)$ de acadêmicos do sexo masculino (Figura 3). Em relação ao quantitativo de participantes de cada período, observou-se que o período com maior número de participantes foi o $7^{\circ}$ com $22(9,5 \%)$ acadêmicos e o período com menor número de participantes foi o $12^{\circ}$ com 15 (6,5\%) (Tabela 1 ).

Feminino

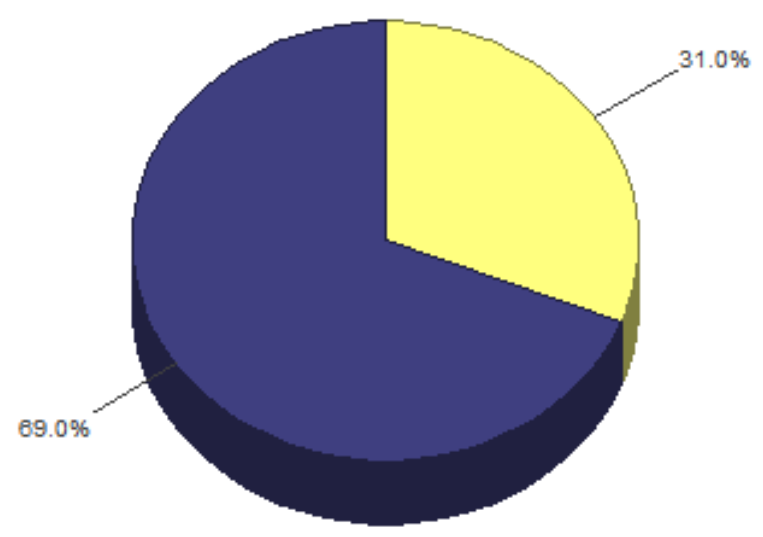

Figura 3. Distribuição quanto ao gênero dos acadêmicos de medicina da Universidade Ceuma

Tabela 1. Distribuição de acadêmicos de medicina da Universidade Ceuma por período.

\begin{tabular}{|c|c|c|}
\hline Período & $\mathbf{N}$ & $\%$ \\
\hline $1 \stackrel{\circ}{\circ}$ & 21 & 9,1 \\
\hline 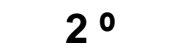 & 21 & 9,1 \\
\hline $3 \stackrel{0}{\circ}$ & 19 & 8,2 \\
\hline $4 \stackrel{\circ}{\circ}$ & 20 & 8,6 \\
\hline $5 \circ$ & 20 & 8,6 \\
\hline 60 & 20 & 8,6 \\
\hline $7 \stackrel{0}{\circ}$ & 22 & 9,5 \\
\hline $8 \stackrel{0}{\circ}$ & 20 & 8,6 \\
\hline 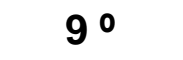 & 17 & 7,3 \\
\hline 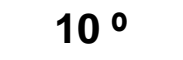 & 20 & 8,6 \\
\hline $11 \stackrel{\circ}{ }$ & 17 & 7,3 \\
\hline $12^{\circ}$ & 15 & 6,5 \\
\hline Total & 232 & 100 \\
\hline
\end{tabular}


As perguntas não sócio demográficas que compunham 0 questionário foram analisadas de acordo com os seguintes aspectos: formação técnica, percepção dos conhecimentos fisiopatológicos, semiologia e terápêuticas associadas à dor, a saber:

\section{1ํ Período:}

Com relação ao manejo de pacientes com dor 90,48\% dos estudantes afirmaram ainda não ter recebido informação suficiente sobre o assunto, 76,19\% acreditam não ter adquirido informação suficiente para controlar os sintomas de pacientes em cuidados paliativos e $71,43 \%$ afirmam NÃO existir disciplina específica para dor em sua faculdade.

De modo geral, neste período, talvez por se tratar de um período inicial no qual os alunos acabaram de iniciar seus estudos, a maioria respondeu negativamente a todas as perguntas do questionário, com exceção da que diz respeito à postura médica e ética para comunicação de más noticias para pacientes e familiares no qual $61,9 \%$ responderam que receberam informações o suficiente.

Quanto ao aspecto terapêutico, como esperado de um período inicial, a grande maioria se sente inseguro em fazer o manejo de pacientes com dor, uma vez que, em média, 95,24\% afirma não possuir conhecimento suficiente sobre a "escada" da OMS para dor ou sobre analgesia.

Desconhecem ainda efeitos, doses e mecanismo de ação dos medicamentos utilizados nessa prática como antidepressivos e anticonvulsivantes. Apenas $19,05 \%$ dos entrevistados desse período afirmaram que seu maior receio no uso de opioides seria a depressão respiratória, já quando questionados sobre a dependência química, 42,86\% consideraram essa como sua maior preocupação no uso dessa classe. Dos alunos avaliados desse período 47,62\% souberam definir a "escada" analgésica da dor (OMS) e 42,86\% identificaram a deficiência da vitamina $D$ como sendo a principal envolvida na dor. Para finalizar, a maioria soube definir ortotanásia, distanásia, eutanásia e suicídio assistido, $71,43 \%, \quad 85,71 \%, \quad 100 \%$ e $61,90 \%$ respectivamente.

\section{2o Período:}

Após um período é perceptivo uma leve mudança sobre o grau de conhecimento dos alunos. Neste a maioria sabe diferenciar a dor nociceptiva e neuropática $(65 \%$ dos que responderam sim), $80 \%$ conhecem alguma escala de dor e $45 \%$ destes, a utilizam com frequência para avaliar os pacientes. Para as demais perguntas, não houve acréscimos significativo de conhecimento.

Quanto ao aspecto terapêutico, mesmo após um período, ainda é perceptível que os entrevistados possuem pouco conhecimento sobre analgesia tendo uma média de $87 \%$ de negativa quando questionados sobre a "escada" da dor da OMS, manejo da mesma em pacientes oncológicos e mecanismo de ação de medicamentos utilizados nesta área.

A dependência química continua sendo a maior preocupação na prescrição de opióides com $65 \%$ e a depressão respiratória com apenas $25 \%$. De modo geral não teve mudanças significativas de conhecimento sobre esse assunto.

\section{3ํo Período:}

Houve mudanças com uma redução daqueles que conhecem alguma escala de dor para $65 \%$ e $15 \%$ destes a utilizam com certa frequência, além disso, $75 \%$ dos alunos sabem diferenciar dor nociceptiva e neuropática, para os demais critérios não houve mudanças significativas.

Quanto ao aspecto terapêutico, não houveram grandes alterações no conhecimento desse período, sendo $96 \%$ a média da taxa de entrevistados que 
afirmam não possuir informações suficientes sobre 0 assunto $e$ a dependência química se mantem como o maior receio com 30\%. Apenas 25\% souberam referir a "escada" da dor (OMS) e com relação à distanásia, houve uma maior distribuição das opiniões com $65 \%$ acertando sua definição. As demais estatísticas se mantiveram semelhantes.

\section{4ํ Período:}

Neste período, 85\% afirmaram existir alguma disciplina voltada para dor, contrastando com os períodos anteriores, apenas $40 \%$ afirmaram saber diferenciar dor nociceptiva e neuropática e 30\% conhece alguma escala de dor o que representa um retrocesso se comparado com o período anterior. Demais respostas sem mudança significativa.

Quanto ao aspecto terapêutico, ainda dentro do esperado, a grande maioria não apresenta conhecimentos 0 suficiente para fazer o manejo do paciente com dor, sendo que $94 \%$ dos entrevistados afirmam não deter tal informação, nesse período $40 \%$ afirmam que a depressão respiratória e a dependência química são seus maiores receios no uso de opióides. Apenas 35\% conhecem a "escada" da dor (OMS) e sem alterações significativas nos demais dados.

\section{5o Período:}

A partir deste período é possível perceber mudanças nas respostas dos alunos, talvez por ser nesse período que o aluno é apresentado ao modulo de dor na universidade em questão.

Metade afirma ter recebido informações suficientes para manejar pacientes com dor, 100\% reconhece que cuidados paliativos não são apenas para pacientes terminais, $80 \%$ afirma ter uma disciplina voltada para dor em sua faculdade, todos relatam saber diferenciar dor nociceptiva e neuropática e conhecer alguma escala de dor, embora apenas $75 \%$ a utilizam com certa frequência.
Apenas 5\% afirmam ter recebido informações suficientes para lidar com pacientes terminais o que explica o fato de apenas $15 \%$ conhecerem o termo testamento vital, 20\% conhecerem a definição da OMS para cuidados paliativos e $25 \%$ saberem o controle de sintomas para esses pacientes.

Quanto aos aspectos terapêuticos, como já dito a partir desse período, os entrevistados adquirem seu primeiro contato com o módulo de dor e isso permitiu perceber certas mudanças em seus conhecimentos sobre o assunto, $80 \%$ afirmaram conhecer a "escada" da dor da OMS sendo que $85 \%$ souberam referir corretamente a mesma, porém ainda é visível sua insegurança quanto ao manejo do paciente, pois, apenas $35 \%$ se sentem seguros para tal ato e embora $100 \%$ conheçam o mecanismo de ação dos anticonvulsivantes, apenas $5 \%$ sabem a dos antidepressivos, e mais uma vez a dependência química se destaca como maior receio com $65 \%$.

Dos alunos avaliados nesse período, $50 \%$ referiram que a deficiência na vitamina $D$ está relacionada ao surgimento de dor e houver maior discrepância quanto a definição de ortotanásia e distanásia, nos quais, respectivamente, $55 \%$ e $50 \%$ souberam definir corretamente. Não houve mudanças significativas nos demais dados.

\section{6o Período:}

Não houve mudanças significativas do último período, com exceção que agora $100 \%$ detém conhecimento sobre a diferença entre dor nociceptiva e neuropática, talvez por isso todos conheçam alguma escala de dor e $65 \%$ destes a utilizam no dia-a-dia.

Quanto aos aspectos terapêuticos, a maioria dos discentes referiu deter conhecimento sobre o assunto com 95\% afirmando conhecer a "escada" do manejo da dor e $85 \%$ referindo-a corretamente, porém ainda persiste a insegurança quanto á utilização desses 
conhecimentos com apenas $35 \%$ afirmando sentir-se seguro em cuidar de pacientes que necessitem de tal atendimento.

A depressão respiratória passou a ser o maior receio com $60 \%$. E apenas $35 \%$ assinalaram a deficiência da vitamina $D$ como estando associada a dor e $40 \%$, 55\%, 95\% e 50\% definiram corretamente ortotanásia, distanásia, eutanásia e suicídio assistido, respectivamente.

\section{7ํ Período:}

Se comparado com o período anterior, neste apenas 14,29\% afirmam ter condições para lidar com pacientes em cuidados paliativos. Isso representa um retrocesso quanto ao manuseio desses pacientes.

Quanto aos aspectos terapêuticos, comparando com os achados do sexto período, não houve grandes mudanças, a maioria ainda mostram-se conhecedores do assunto com $42,86 \%$ se sentindo seguros em fazer o manejo da analgesia no paciente oncológico.

Dos avaliados neste período, 38,1\% afirmam saber prescrever opioides e quanto ao mecanismo de ação dos antidepressivos e anticonvulsivantes, $61,9 \%$ e $42,86 \%$, respectivamente, relatam ter tal conhecimento (o que denota dados preocupantes já que este é um período avançado e os discentes já passaram pelos conhecimentos aplicados no módulo de dor).

Novamente a dependência química se destaca como maior receio no uso de opióides com $61,9 \%$ dos entrevistados. Quanto à definição de ortotanásia e distanásia apenas $38,1 \%$ e $42,86 \%$ acertaram (isso pode revelar certa fragilidade no ensino já que houve redução se comparado aos períodos anteriores). Nos demais dados, não houveram variações significativas.

\section{Período:}

A partir do 5ำ Período, não há muitas mudanças na distribuição das respostas. Apenas 15\% conhecem a definição da OMS para cuidados paliativos e $25 \%$ o que é o testamento vital, $85 \%$ sabem diferenciar dor nociceptiva e neuropática, todos conhecem alguma escala de dor, porém apenas $85 \%$ destes a utilizam.

Quanto aos aspectos terapêuticos, é visível um retrocesso se comparado aos períodos anteriores, pois, apenas $65 \%$ afirmam deter conhecimento sobre a "escada" da OMS com $60 \%$ conhecendo a escada analgésica, $10 \%$ se sentem seguros á fazer o manejo da analgesia em pacientes oncológicos e $15 \%$ em prescrever opioides, $75 \%$ possuindo como maior receio destes a depressão respiratória.

Apenas $20 \%$ referiram a deficiência na vitamina $D$ como causa de dor e com relação a definição de ortotanásia e distanásia $50 \%$ o fizeram corretamente, não possuindo outras alterações significativas nos demais dados.

\section{9o Período:}

Houve um aumento se comparado com o período anterior já que 47,06\% conhecem a definição da OMS para cuidados paliativos, porém, para as demais perguntas, não houve uma variação tão significativa.

Quanto aos aspectos terapêuticos, houve uma melhora nos dados, com $82,35 \%$ relatando conhecer a "escada" da OMS e 58,82\% sabendo referi-la corretamente, $41 \%$ se sentem seguros em manejar a analgesia de pacientes oncológicos e 35\% em prescrever opioides com $70 \%$ temendo a depressão respiratória que estes podem desencadear.

Dos alunos avaliados neste período, $58,82 \%$ sabem como funcionam os antidepressivos e $41,18 \%$ os anticonvulsivantes. Apenas 47,06\% associaram a deficiência da vitamina $D$ com dores e com exceção do suicídio assistido com apenas 35,29\% de acertos, mais de $70 \%$ dos entrevistados souberam definir corretamente 
ortotanásia, distanásia e eutanásia.

\section{0ํ Período:}

Sem variações significativas se comparado com 0 anterior. Isso pode representar certa equidade de conhecimentos presente nesses dois períodos.

Quanto aos aspectos terapêuticos, não houveram mudanças significativas quanto comparado ao nono período, de modo geral os discentes afirmam conhecer o manejo da dor e seu maior receio em prescrever opioides é a depressão respiratória. Agora $70 \%$ afirmam conhecer o funcionamento dos antidepressivos e $60 \%$ o dos anticonvulsivantes.

Dos avaliados nesse período, $60 \%$ souberam referir a "escada" analgésica da OMS e $35 \%$ associaram a deficiência de vitamina $D$ com o surgimento de dor. Por fim, mais de $70 \%$ dos entrevistados souberam definir ortotanásia, distanásia, eutanásia e suicídio assistido.

\section{1ํ Período:}

É possível perceber que mesmo em um período tão avançado, ainda há alunos que acreditem que cuidados paliativos sejam apenas para pacientes oncológicos terminais $(11,76 \%)$ sendo que $35,29 \%$ não conhecem a definição de cuidados paliativos pela OMS e $88,24 \%$ ainda acreditam não ter tido informação o suficiente para lidar com pacientes terminais, $76,47 \%$ ainda não sabem o que é um testamento vital.

Do montante, $11,76 \%$ não sabem diferenciar dor nociceptiva e neuropática, e embora todos conheçam alguma escala de dor apenas $58,82 \%$ a utilizam de forma efetiva e apenas $52,94 \%$ acreditam ter conhecimento o suficiente para "dar más noticias".

Quanto aos aspectos terapêuticos, nesse período, 94,12\% afirmaram conhecer a "escada" da OMS, mas apenas $52,94 \%$ souberam referi-la corretamente, $58,82 \%$ se sentem seguros em prescrever opioides e possuem como maior receio tanto a depressão respiratória quanto a dependência química que esta classe pode provocar (afirmação de 47,06\% em ambos).

Apenas $23,53 \%$ afirmam que a deficiência de vitamina $D$ é a causadora de dores e apenas $29,41 \%$ definiram corretamente suicídio assistido e nas demais (ortotanásia, distanásia e eutanásia) houve um acerto acima de $70 \%$.

\section{2º Período:}

Já é notória a diferença dos períodos anteriores, uma vez que todos negam que cuidados paliativos sejam apenas para pacientes terminais oncológicos e todos reconhecem não ter recebido informações o suficiente para lidar com tais pacientes, porém apenas $13.33 \%$ sabem o que é Testamento Vital. As demais questões foram respondidas de forma semelhante.

Quanto aos aspectos terapêuticos, ao analisar as respostas, é possível perceber que não houve mudanças significativas nos conhecimentos, mesmo se comparado a períodos iniciais, pois embora $80 \%$ afirmem conhecer a "escada "da OMS, apenas 40\% souberam referi-la.

Somente $46,87 \%$, associaram a vitamina $D$ como causadora da dor, como os demais períodos, a taxa de acerto ao definir ortotanásia, distanásia, eutanásia e suicídio assistido foi acima de $70 \%$.

O único ponto diferente dos períodos iniciais é que afirma, em maior quantidade, ter segurança em prescrever opióides e mesmo assim alcançam apenas $40 \%$, porcentagem média em todos os demais períodos, isso gera certa preocupação, visto que é baixo tal conhecimento para alunos que logo se tornarão médicos e lidarão com pacientes em sofrimento álgico.

Em tempo, cabe citar que em todos os períodos foi praticamente unânime que ainda faltam conhecimentos sobre o tratamento de pacientes com dor e de modo geral, a partir do 5o período, aonde 
é apresentado o módulo de dor, as respostas começam a se alterar, mas não de forma significativa, evidenciando que o conhecimento e manejo da dor passam a ser mais bem consolidados a partir desse período, mesmo não sendo concretizado por completo, até a finalização da graduação.

Agora segue uma coletânea de gráficos comparativos envolvendo 0 conhecimento geral e terapêutica da dor e dos cuidados paliativos aplicados aos acadêmicos do curso de medicina da Universidade Ceuma, divididos por ciclos, a saber:

1) Ciclo Básico (compreendendo do 1은 aos 4ํํㅁodos);

2) Ciclo Pré-Clínico (compreendendo do $5^{\circ}$ aos $8^{\circ}$ períodos);

3) Ciclo Clínico (compreendendo do 9o aos $12^{\circ}$ períodos).

\section{Discussão}

Os respectivos alunos foram avaliados por períodos, a fim de identificar a existência de possíveis lacunas de aprendizado sobre a temática, evidenciando que a maioria dos alunos não se sentem seguros quanto a abordagem de pacientes em Cuidados Paliativos.

Os questionários respondidos foram analisados de acordo com os seguintes aspectos: formação técnica, percepção dos conhecimentos fisiopatológicos, semiologia e terapêutica associadas a dor e cuidados paliativos. Este questionário foi utilizado em um estudo semelhante dos estudantes de medicina no Estado de São Paulo, ano 2010. Os resultados mostram um conhecimento razoável sobre dor e definições em cuidados paliativos ${ }^{16}$.

Cerca de $40 \%$ dos estudantes de São Paulo acreditam ter recebido informação suficiente sobre o manejo de pacientes com dor e a metade deles acredita ter recebido informação suficiente sobre o controle de sintomas em pacientes terminais, porém a totalidade $(100 \%)$ dos estudantes referiu que não existe uma disciplina específica de dor em suas Faculdades. ${ }^{11}$

A maioria dos alunos não conhece a definição de Cuidados Paliativos da Organização Mundial de Saúde (61\%), e não se sente à vontade para comunicar más notícias aos pacientes e familiares ${ }^{17,18}$. O que difere do presente estudo, metade afirma ter recebido informações suficientes para manejar pacientes com dor, $100 \%$ reconhece que cuidados paliativos não são apenas para pacientes terminais, $80 \%$ afirma ter uma disciplina voltada para dor em sua faculdade, pois a partir do $5^{\circ}$ período, o aluno é apresentado ao módulo na universidade em questão.

Conforme a experiência já documentada o contato com os pacientes paliativos sob orientação dos médicos reforça a ideia de que um ambiente mais específico pode propiciar uma melhor formação técnica.

\section{Conclusão}

Através desse estudo foi possível identificar o perfil dos acadêmicos de medicina da Universidade Ceuma e consequentemente dos egressos formados por essa instituição quanto aos conhecimentos adquiridos e sedimentados durante a graduação no que tangencia os cuidados paliativos e também manejo da dor.

Via de regra é sabido que o conjunto teórico-prático transmitido ainda na graduação, aliado à criação de um ambiente propício a simulações realísticas ou vivências práticas, podem interferir na educação médica de forma positiva.

Dessa forma, frente aos resultados aqui apresentados no que tangencia a fragilidade dos conhecimentos estudantis sobre a temática acreditamos que 


atividades didáticas em cenários
destinados à prática de Cuidados
Paliativos, como ambulatórios
especializados, simulações realísticas e
disciplinas direcionadas a temática,
devem compor e fazer parte do currículo
da graduação médica.
Assim, acredita-se que a criação de
uma disciplina específica para Cuidados
Paliativos, não apenas a vivência de um
módulo curricular no prazo de 1 mês e
meio aproximadamente, poderia sanar as
deficiências educacionais aqui
levantadas nos graduandos e eventuais
egressos.

\section{Referências}

1. Organização Mundial de Saúde (OMS). Conferência Internacional sobre Cuidados Primários de Saúde: Declaração de Alma-Ata, 1978. Brasília, DF: Ministério da Saúde, 2004.

2. Instituto Nacional de Câncer (INCA). ABC do câncer: abordagens básicas para o controle do câncer. Rio de Janeiro: INCA, p. 128, 2011.

3. Araújo MMT, Silva MJP. A comunicação com o paciente em cuidados paliativos: valorizando a alegria e o otimismo. Rev. Esc. Enferm. USP., São Paulo, v. 41, 2007, p. 4.

4. Maciel MGS. Definições e princípios. In: Oliveira RA, coordenador. Cuidados Paliativos. São Paulo: Conselho Regional de Medicina do Estado de São Paulo; p.215-32, 2008.

5. Bernardo, C.L.E. et al. Educação em Cuidados Paliativos na rede municipal de saúde de Campinas. In: Congresso Internacional de Cuidados Paliativos, 4., 2010, São Paulo. Anais... São Paulo, v. 4, p. 14-16, 2010.

6. Ministério da Saúde. Agência Nacional de Vigilância Sanitária. Resolução ANVISA Regulamenta as Unidades de Terapia Intensiva. Norma do MS de 24 de fevereiro de 2010 publicada no DOU: v.25.p. 02. 2011

7. Lemos AM, Santana NS. Cuidados paliativos: o olhar de uma graduanda de enfermagem. Revista Enferm Unisa; v. 12(1): p. 52-z, 2011.

8. Matos FA, Moraes TM. A enfermagem nos cuidados paliativos. In: Figueiredo MTA, coordenador. Coletânea de textos sobre cuidados paliativos e tanatologia. São Paulo: UNIFESP; p. 49-61, 2006.
9. Montanha D, Peduzzi M. Educação permanente em enfermagem: levantamento de necessidades e resultados esperados segundo a concepção dos trabalhadores. Rev. Esc. Enferm. USP. 2010 set;44(3):597-604

10.Peduzzi M. Equipe multiprofissional em saúde: conceito e tipologia. Revista Saúde Pública; v. 1(35): p103-109, 2004.

11. Peduzzi M. Equipe multiprofissional de saúde: a interface entre trabalho e interação (Tese). Campinas: Faculdade de Ciências Médicas, Universidade Estadual de Campinas, 1998.

12.Florian CA, Schramm FR. Desafios morais e operacionais da inclusão dos cuidados paliativos na rede de atenção básica. Cad. Saúde Pública, Rio de Janeiro, v. 23(9): p. 2072-2080, set, 2007.

13.Conselho Federal de Medicina (CFM). Código de Ética Médica. Resolução CFM № 1931/2009. Publicada no D.O.U. de 24 de setembro de 2009.

14. Conselho Federal de Medicina (CFM). "Resolução CFM № 1.973/2011". Dispõe sobre a criação da especialidade Medicina Paliativa no Brasil. Publicada no D. O. U. de $1^{\circ}$ de agosto de 2011. Seção: v. I, p. 144-147, 2011.

15. Conselho Federal de Medicina (CFM). Resolução CFM no1.995/2012. Dispõe sobre as diretivas antecipadas de vontade dos pacientes. Publicada no D.O.U. de 31 de agosto de 2012. Seção: v. I, p.269-70, 2012.

16. Associação de Medicina Intensiva Brasileira (AMIB): Fórum Permanente MERCOSUL para o Trabalho em Saúde. Outubro, 2007. Disponível em: www.amib.com.br. Acesso em: 11 abril. 2016.

17.Schramm FR. Morte e finitude em nossa sociedade: implicações no ensino dos Cuidados Paliativos. Revista Brasileira Cancer; v. 48(1); p.17-20, 2002.

18. Silva RCF, Hortale VA. Cuidados paliativos oncológicos: elementos para o debate de diretrizes nesta área. Cad. Saúde Pública, Rio de Janeiro, v. 22(10); p.2055-2066, out, 2006. 